CZU 343.352

DOI: https://doi.org/10.52388/2345-1971.2021.1.05

\title{
CONSTITUTIONAL FRAMEWORK FOR THE DEVELOPMENT OF SELF-REGULATORY ORGANIZATIONS AS A WAY OF PROTECTION AGAINST CORRUPTION
}

\author{
Vasilii IGNATIEV \\ Doctor of Law, University Professor, Comrat State University, \\ Comrat, Republic of Moldova \\ e-mail: ivasily022@mail.ru \\ https//orcid.org/0000-0002-9037-4422
}

\begin{abstract}
The article reveals the reasons for the occurrence of various types of corruption and the classification of anti-corruption measures. The object of research is a complex of legal and non-legal relations that arise at the initial stages of the appearance of various forms and varieties of corruption. The purpose of this paper is to study the external and internal factors of the emergence of systemic corruption and to develop proactive methods for its weakening and disappearance at all levels of government and self-government. Ways are proposed to weaken corruption by developing self-regulatory organizations of entrepreneurs and delegating them to certain state functions. The relevance of the topic is due to the fact that corruption is a universal property of any state, a property that, potentially, under certain conditions of social life, can lead to the emergence of problems that call into question the very existence of the state. The author also believes that it is necessary to take concrete practical measures in the direction of changing imperfect legal norms in the form of stricter control over departmental regulation and conducting permanent expertise of "anti-corruption"legislation.
\end{abstract}

Keywords: corruption, electoral corruption, constitutional uncertainty, abuse of public power, anticorruption, self-regulatory organizations.

\section{CADRUL CONSTITUȚIONAL DE DEZVOLTARE AL ORGANIZATTIILOR DE AUTOREGLEMENTARE CA MODALITATE DE PROTECTIIE CONTRA CORUPȚIEI}

Articolul dezvăluie motivele apariției diferitelor tipuri de corupție și clasificarea măsurilor anticorupție. Obiectul cercetării este un complex de relații juridice și non-juridice care apar în etapele inițiale ale apariției diferitelor forme și varietăți de corupție. Scopul prezentei lucrări este de a studia factorii externi și interni ai apariției corupției sistemice și de a dezvolta metode proactive pentru slăbirea și dispariția acesteia la toate nivelurile de guvernare și autoguvernare. Sunt propuse modalități de slăbire a corupției prin dezvoltarea organizațiilor de autoreglementare a antreprenorilor și delegarea acestora anumitor funcții ale statului. Relevanța subiectului se datorează faptului că corupția este o proprietate universală a oricărui stat, o proprietate care, potențial, în anumite condiții ale vieții sociale, poate duce la apariția unor probleme care pun in pericol însăși existențta statului. De asemenea, autorul susține opinia referitor la necesitatea de a se lua măsuri practice concrete în direcția modificării normelor juridice imperfecte sub forma unui control mai strict asupra reglementării departamentale și a efectuării expertizei permanente a legislației ,,anticorupție”.

Cuvinte-cheie: corupție, corupție electorală, incertitudine constituțională, abuz de putere publică, anticorupție, organizații de autoreglementare. 


\section{CADRE CONSTITUTIONNEL POUR LE DÉVELOPPEMENT D'ORGANISATIONS D'AUTORÉGLEMENTATION COMME MOYEN DE PROTECTION CONTRE LA CORRUPTION}

L'article révèle les raisons de l'apparition de divers types de corruption et la classification des mesures anticorruption. L'objet de la recherche est un complexe de relations juridiques et non juridiques qui se posent aux stades initiaux de l'émergence de diverses formes et variétés de corruption. Le but de cet article est d'étudier les facteurs externes et internes de l'émergence de la corruption systémique et de développer des méthodes proactives pour son affaiblissement et sa disparition à tous les niveaux de gouvernement et d'autonomie. Des moyens sont proposés pour affaiblir la corruption en développant des organisations d'autoréglementation des entrepreneurs et en les déléguant à certaines fonctions de l'État. La pertinence du sujet est due au fait que la corruption est une propriété universelle de tout État, une propriété qui, potentiellement, dans certaines conditions de la vie sociale, peut entraîner l'émergence de problèmes qui remettent en cause l'existence même de l'État. L'auteur estime également qu'il est nécessaire de prendre des mesures pratiques concrètes pour modifier les normes juridiques imparfaites sous la forme d'un contrôle plus strict de la réglementation départementale et d'une expertise permanente de la législation "anti-corruption".

Mots-clés: corruption, corruption électorale, incertitude constitutionnelle, abus de pouvoir public, lutte contre la corruption, organisations d'autoréglementation.

\section{КОНСТИТУЦИОННЫЕ ОСНОВЫ РАЗВИТИЯ ОРГАНИЗАЦИЙ САМОРЕГУЛИРОВАНИЯ КАК СПОСОБ ЗАЩИТЫ ОТ КОРРУПЦИИ}

В статье раскрываются причины появления различных видов коррупции и классификация мер по противодействию коррупции. Объект исследования - комплекс правовых и неправовых отношений, возникающих на начальных стадиях появления различных видов и разновидностей коррупичи. Целью данной работы является исследование внешних и внутренних факторов появления системной коррупции и разработка упреждающих методов ее ослабления и исчезновения на всех уровнях государственного управления и самоуправления. Предлагаются пути ослабления коррупичи за счет развития организаций саморегулирования предпринимателей и делегирования им некоторых функичии государства. Актуальность темы обусловлена тем, что коррупция - универсальное свойство любого государства, свойство, которое потенциально, в определенных условиях социального бытия, может привести к появлению проблем, ставящих под сомнение само существование государства. Автор также придерживается мнения о необходимости реализации конкретных практических шагов в направлении борьбы с несовершенными нормами права в виде ужесточения контроля над ведомственным нормотворчеством и учреждения постоянно действующей экспертизы законодательства на «антикоррупиионность».

Ключевые слова: коррупциия, электоральная коррупцุия, конституционная неопределённость, злоупотребление публичной властью, противодействие коррупщии, организации саморегулирования.

\section{Введение}

Предмет исследования настоящей статьи - разработка организационноправовых мер по противодействию коррупции за счет создания в сообществах предпринимателей саморегулируемых организаций в целях передачи им некоторых функций государства (принятие своего устава, кодекса чести, арбитражного суда и отраслевого нормотворчества). Объект исследования - комплекс правовых и не- правовых отношений, возникающих на начальных стадиях появления различных видов и разновидностей коррупции.

Цель статьи. Основная цель работы это исследование внешних и внутренних факторов появления системной коррупции и разработка упреждающих методов ее ослабления и исчезновения на всех уровнях государственного управления и самоуправления. 
Методы исследования. При подготовке статьи использованы следующие теоретические методы исследования: диалектический, системно-структурный, сравнительноправовой, теоретико-прогностический.

\section{Изложение основного материала}

Конституционно-правовая наука и коррупция, по мнению многих государствоведов, стоят далеко порознь, и только когда коррупция поражает весь механизм государства, когда она принимает государствообразующие формы, становясь частью государственной системы, то есть системной коррупцией, только тогда конституционное право обязано оценить проблему коррупции и проявить интерес к ранее не свойственной ему проблематике [1, с. 18].

Однако, как показывает опыт борьбы с коррупцией, даже четко разработанной системы превентивных мер подчас бывает недостаточно. Реформирование сферы услуг, снижение силы мотивов чиновников для вступления в коррупционные отношения, расширение прозрачности государственной деятельности следует признать наиболее очевидными целями борьбы с коррупцией. Низкий уровень заработной платы чиновников, закрытость или даже секретность финансирования являются далеко не самыми существенными условиями коррупции. Существует точка зрения, что коррупция основана не на конституционных нормах, а на законах или иных подзаконных актах, способствующих ее возникновению.

Однако, по нашему мнению, коррупцию в рамках конституционного права можно исследовать и раньше, так как государственный механизм в демократических странах, в первую очередь, зачастую поражается коррупцией через один из главных институтов отрасли конституционного права - избирательное право и избирательный процесс.
Когда мы говорим о коррупции, то мало кто из нас задумывается об электоральной коррупции, а именно через неё коррупция проникает в государственную систему всех ветвей власти, поражая государственный механизм целиком. Тем более, что в Республике Молдова действует многопартийная система и некоторые избранники отдельных партий уже после их избрания в Парламент РМ или местные органы власти становятся «перебежчиками» из одной партии в другую за определенное денежное вознаграждение и т.п.

К сожалению, Конституция Республики Молдова, в отличие от конституций других стран (Германии, Франции, США и др.), обходит стороной тему выборов, как квинтэссенцию демократического управления и народовластия, почти не содержат норм материального права и не давая конкретных указаний на этот счет, а такой важнейший элемент политической системы, призванный удовлетворять потребность граждан в участии в политической жизни государства и в управлении государством, как политическая партия, в Конституции РМ отсутствует полностью. Именно такая конституционно-правовая неопределённость, по нашему мнению, создаёт первичные, базовые условия для возникновения коррупции в Молдове.

Неизбывность коррупции, ее функциональный (наряду с дисфункциональным) характер, порождают подозрение в том, что она укоренена в государственном аппарате. Это подозрение находит свое подтверждение в наиболее общем и наиболее распространенном определении коррупции. Согласно ему коррупция - это злоупотребление публичной властью в личных интересах. Институциональные корни коррупции - в отношении агент-принципал между государством и чиновником, с одной стороны, которое и позволяет чиновнику (агенту) злоупотреблять использованием ресурсов 
государства (принципала) в двух формах: либо непосредственно в своих интересах (например, в виде казнокрадства), либо, с другой стороны, за ренту, в интересах других индивидов и их групп, например, предпринимателей (с помощью взятки и т.д.). Иными словами, насколько сущность государства допускает конфликт интересов между государством, чиновником и предпринимателем, настолько и существует высокий уровень коррупции.

Следовательно, коррупцию нельзя рассматривать всего лишь как симптом плохого управления, как предлагает ряд авторов. А поскольку коррупция укоренена в самой сути государства, так как именно она предполагает агентские (в гражданско-правовом смысле) отношения, постольку и цель борьбы с коррупцией - не в ее искоренении, а в ее минимизации. Отсюда следует также призрачность успеха борьбы с коррупцией методом «сильной руки» (об этом методе и его неэффективности $c м$. ниже).

О широком распространении в Республике Молдова произвола и коррупции, которые допускаются, а в отдельных случаях, и предполагаются законом, свидетельствует тот факт, что даже Конституционный Суд не раз указывал молдавскому законодателю на необходимость ответственнее подходить к своей основной обязанности - законотворчеству.

Меры по противодействию коррупции можно подразделить на три достаточно общие группы. В первую группу входят меры борьбы с внешними проявлениями коррупции (взятки конкретным чиновникам), с уже существующей коррупцией, с конкретными коррупционерами, во вторую - с институциональными предпосылками, обусловливающими коррупцию, с потенциальной коррупцией, с тем безличным коррупционером, в которого может, при определенных обстоятельствах, превратиться чиновник. В третью группу входят организационно-правовые и воспитательные меры в сообществах предпринимателей (союзы, саморегулируемые организации и т.п.) в целях передачи им некоторых функций государства (принятие своего устава, кодекса чести, арбитражного суда и отраслевого нормотворчества). Из этого разграничения нетрудно заметить следующее.

Bo-nepвыx, первая группа мер будет носить карательный характер, который выражается в ужесточении государственного контроля.

Bo-вторых, карательные меры будут приводить к новому витку коррупции еще и по следующим соображениям. С одной стороны, каждая из мер, направленных на снижение коррупции, связана с затратами на получение информации, на поимку коррупционеров, на их осуждение и так далее. Чем больше коррупционеров, тем больше затраты на их поимку. С другой стороны, уровень потерь для коррупционера растет в связи с применением достаточно суровых мер наказания. Иными словами, коррупция существует вследствие того, что прибыль должностного лица, привлекающего нарушителя к ответственности гораздо ниже, чем наказание потенциального нарушителя ${ }^{2}$ прибыль должностного лица падает или остается неизменной, а уровень наказания потенциального коррупционера растет, что и приводит к росту коррупции.

$\boldsymbol{B}$-третьих, борьба с коррупцией в рамках первого метода, целью которой является сам коррупционер, а не коррупция, будет носить характер борьбы Геракла с гидрой, у которой постоянно вырастают новые головы, что обусловливает циклический характер искоренения коррупции.

B-четвертых, в рамках данного подхода, «с коррупцией среди государственного аппарата боролись исключительно представители этого аппарата. Это приводило 
к двум последствиям: боровшиеся были органически не в состоянии менять коренные причины, порождающие коррупцию, поскольку они восходили к важнейшим условиям существования системы; борьба против коррупционеров нередко перерастала в борьбу против конкурентов на рынке коррупционных услуг» [2, p.465].

B-nятых, обнадеживаюшая возможность развивать организации саморегулирования предпринимателей и ослабления коррупщии или даже ее искоренения, за счет делегирования им определенных функций государства [3, с13].

Наиболее четкое представление о первой группе мер можно получить, изучая историю борьбы с коррупцией в Китае [4, Vol. 34]. Ее начало датируется декабрем 1951 года, когда на всей территории Китая начиналась программа под названием «три анти-» (анти-коррупция, антибюрократизм, анти-расточительство). Тысячи людей приговаривались к смертной казни за вступление в коррупционные отношения. Учреждались специальные народные суды, которые рассматривали исключительно дела о коррупции. Правительство требовало от каждого человека сообщать о ставших ему известных случаях коррупции. Официально кампания закончилась в июне 1952 года. Результаты акции кажутся поразительными. Число зарегистрированных случаев коррупции упало с 500 тыс. в 1950 году до 290 тыс. в среднем за период с 1951 до 1965 года. Коррупция в это время была настолько низка, что позволяет Г. Мурдалу назвать Китай «страной дисциплинированного государства, которое по меркам Южной Азии чрезвычайно честно» [5, p.232].

После Культурной революции, которая началась в 1966 году, коррупция опять привлекла всеобщее внимание. В 1982 году Центральный Комитет КПК начал новую компанию против коррупции. Ее проведение было затруднено тем, что, по сравнению с предыдущим периодом обострения, резко возросла теневая коррупция. Это связано прежде всего с тем, что чиновники выработали «антитела» на кампании против коррупции и сформировали устойчивые коалиции, в рамках которых «покрывали» друг друга. Государство противодействовало этому реорганизацией контролирующих органов и принятием специальных законов, дополняющих уголовный кодекс и предусматривающих более суровые наказания за вступление в коррупционные отношения. Результаты этой кампании оказались гораздо более скромными. Основным объяснением этому служит предположение о том, что чиновники, предвидя визит контролирующих органов, формировали «наступательные и оборонительные союзы». Центральный дисциплинарный комитет КНР начал сталкиваться с серьезными проблемами в выявлении коррупционных практик. Связано это было с тем, что в них вовлечены высокопоставленные чиновники, предоставляющие поддержку своим подчиненным. Подчас сообщение о коррупционной практике, посылаемое одним из чиновников наверх, перехватывалось его начальником либо коалицией его сослуживцевкоррупционеров. Другими словами, первая волна (цикл) борьбы против коррупции привела к формированию коррупционных сетей, то есть - к новому качественному уровню коррупции.

Объяснение циклов вполне очевидно - в Китае в то время боролись с симптомами проблемы, а не с проблемой, с коррупционерами, а не с источниками возникновения коррупции.

Вторая группа мер носит превентивный, а не карательный характер, направлена против причин, а не внешних выражений коррупции, и поэтому лишена многих недостатков, присущих «методу войны». Меры превентивного характера были собраны 
сотрудниками Мирового банка в единую многоцелевую стратегию борьбы с коррупцией. Она состоит из пяти разделов:

\section{1. Институциональные основы:}

- институционализация независимой и эффективной судебной власти;

- расширение сферы действия парламентского контроля;

- обеспечение независимости правоохранительных органов.

\section{2. Политическая ответственность:}

- политическая конкуренция, заслуживающие доверия политические партии; тий;

- прозрачность в финансировании пар-

- прозрачность процедуры голосования для избирателей;

- обязанность госслужащих декларировать имущество, правила, регулирующие вопрос конфликта интересов.

3. Расиирение возможностей участия гражжданского общества: ции;

- гарантирование свободы информа-

- усиление роли СМИ.

4. Конкурентный частный сектор:

- реструктуризация монополий с целью повышения конкурентности;

- снижение барьеров входа на рынок, связанных с необходимостью получения различных разрешений;

- прозрачность корпоративного менеджмента;

- увеличение прав деловых ассоциаций.

5. Управление государственным сектором:

- найм на государственную службу на основе заслуги, достойная оплата труда государственных служащих;

- децентрализация власти;

- повышение прозрачности бюджетного процесса для контролирующих органов;

- повышение прозрачности в налоговой администрации, лишение налоговых служащих возможности произвольно предоставлять налоговые льготы, упрощение налоговой администрации.

К сожалению, как в этой работе, так и во многих других сферах, посвященных проблематике борьбы с коррупцией, из поля зрения почти полностью исчезает проблема несовершенства законодательства как фактора, способствующего расцвету коррупции, а, следовательно, и как явления, которое необходимо учитывать в стратегии противодействия ей. Касаясь проблемы законодательства, в большинстве случаев предложения ограничиваются оптимальным дизайном законов против коррупции, без учета того, что в переходное время сам закон против коррупции может способствовать ее появлению.

На наш взгляд, среди прочих прямых антикоррупционных мер необходимо совершенствование законодательства, которое должно осуществляться по следующим направлениям:

- распутывание противоречий и прояснение туманностей в действующем законодательстве, поскольку все это создает возможность для чиновного произвола и коррупции;

- «закрытие» многочисленных отсылочных норм в действующих законах;

- ревизия шкалы наказаний за коррупционные действия с учетом того, что часто завышенные наказания мешают доказательству преступлений;

- дифференцирование в Уголовном кодексе коррупционных действий;

- пересмотр шкал пошлин, штрафов и т.п. (слишком высокие штрафы так же неэффективны, как и слишком низкие, поскольку стимулируют уход от них с помощью взятки);

- развитие организаций саморегулирования предпринимателей.

Конституционные положения, в силу их повышенной стабильности и жесткости, 
не подходят для регулирования рыночных отношений, в том числе в области предпринимательства. Их роль заключается в другом - гарантировать устойчивость и предсказуемость законодательства о предпринимательстве, основывающегося на ст. 16 Хартии Европейского союза об основных правах, которая называется, «Свобода предпринимательской деятельности» и в которой зафиксировано, что «Свобода предпринимательской деятельности признается в соответствии с коммунитарным правом и с национальным законодательством и национальной практикой» [5]. С учетом перспективы вступления Республики Молдова в ЕС было бы целесообразно в главе II «Основные права и свободы» Конституции Республики Молдова после ст. 33, предусмотреть ст. 33* «Свобода предпринимательской деятельности и саморегулирования» следующего содержания:

(1) Свобода предпринимательской деятельности признается и гарантируется в рамках рыночной экономики и осуществляется с соблюдением законодательства, включая различные формы коммерции, посредничества и малого бизнеса.

(2) Государство может вмешиваться в организацию экономической, коммерческой, финансовой и трудовой жизни для обеспечения в рамках рыночной экономики сбалансированного развития общества и недопущения незаконных спекулятивных сделок в целях установления справедливых социальных отношений.

(3) Саморегулирование - это самостоятельная форма объединения предпринимателей и предпринимательских сообществ, при которой создающаяся добровольно организация саморегулирования самостоятельно устанавливает цели, задачи, функции, полномочия, права, обязанности и механизм взаимной ответственности между субъектами малого бизнеса внутри этой организации и упорядочивает свои отношения с государством путем представления в соответствующий орган акт саморегулирования (кодекс поведения, правило по урегулированию споров в собственном суде), а государство авторизует его (соглашается, легитимирует) и может делегировать ей часть своих полномочий по регулированию рынка в соответствующей отрасли на контрактной основе [6, с.10].

Самое важное изменение концептуального подхода к предпринимательству - это помещение ст. 33* в главе 2 Конституции РМ, посвященной правам и свободам человека и гражданина, как это имеет место, например, в части 4 ст. 26 Конституции Республики Казахстан, в п.1 ст. 34 Конституции Российской Федерации, в ст. 38 Конституции Королевства Испании 27 февраля 1978 года и др.

Так, например, ст. 42 Конституции Украины гласит «Каждый имеет право на предпринимательскую деятельность, не запрещенную законом» [7].

Даже в княжествах и королевствах Европейского Союза гарантируется свобода предпринимательства. Так, согласно ст. 38 Конституции Королевства Испания 27 февраля 1978 года «признается свобода предпринимательства в рамках рыночного хозяйства». При этом, «публичные власти гарантируют и охраняют ее осуществление в соответствии с общими экономическими требованиями и обеспечивают его производительность, и в случае необходимости в соответствии с требованиями планирования» [8]. В статье 28 Конституции Княжества Андорра от 14 марта 1993 года также зафиксировано, что «свободное предпринимательство признается в рамках рыночной экономики и осуществляется с соблюдением законодательства» [8]. В ст. 32 этой же Конституции указано, что «государство может вмешиваться в организацию экономической, коммерческой, финансовой и 
трудовой жизни для обеспечения в рамках рыночной экономики сбалансированного развития общества, а также общего благосостояния».

Трактовка предпринимательства через призму прав человека и саморегулирования позволяет утверждать, что отношения государства и предпринимателей являются отношениями равных партнеров и у них имеются взаимные права и обязанности. При этом, все формы предпринимательства, включая и малое предпринимательство, можно рассматривать в следующих ракурсах:

Bo-nервыx, как форму реализации конституционного права на осуществление свободы предпринимательства и не запрещенных законом видов экономической деятельности.

Bo-вторых, как форму реализации права на труд. Необходимо отметить, что малое предпринимательство как раз и создает наибольшее количество рабочих мест.

$\boldsymbol{B}$-mpemьих, как разновидность предпринимательской деятельности и иных малых форм, подпадающих и не подпадающих под действие законодательства о предпринимательстве, но которые также должны иметь конституционные основы и право на свое существование и развитие.

$\boldsymbol{B}$-четвертых, как среду формирования организаций саморегулирования. [9,с.72].

Помимо этого, необходимо предпринять конкретные практические шаги в направлении борьбы с несовершенными нормами права в виде ужесточения контроля над ведомственным нормотворчеством и учреждения постоянно действующей экспертизы законодательства на «антикоррупционность».

Следует также отметить, что меры по борьбе с несовершенствами законодательства, повышающими вероятность коррупции, уже были опробованы на практике в Российской Федерации.
Несовершенства норм права, повышающих вероятность коррупции, можно разделить на следующие группы:

1. Для исполнения нормы права индивид вынужден затратить слишком много ресурсов, что вызывает у него желание заплатить за неисполнение данной нормы права. В данную категорию входят материальные нормы, которые либо требуют от субъекта права слишком многого, либо процессуальные нормы права, которые допускают наложение дополнительных потерь в процессе привлечения к ответственности. В качестве фактора, увеличивающего потери можно назвать и «пересечение» контрольных полномочий правоприменительных органов. Количество проверок резко увеличивает потери для экономического агента, и, тем самым, предоставляет коррумпированному чиновнику возможность вступить в договорные отношения.

2. Нормы права дают должностному лицу возможность выбирать между различными вариантами поведения по своему усмотрению.

3. Нормы права, регулирующие поведение должностного лица, отсутствуют, позволяя ему тем самым вести себя по своему усмотрению. Данный случай тесно связан со второй группой коррупциогенных норм. «Демаркационная линия» разделяет случаи предоставления дискреционных полномочий из благих побуждений (например, относительно определенные альтернативные санкции в административном процессе), и ошибки в нормотворческом процессе, допускающие пробелы права.

4. Нормы права наделяют должностное лицо либо ведомство правом разрабатывать и принимать нормативные акты. В данной категории рассматривается частный случай «присвоения государства» (state capture). Проще говоря, присвоение государства представляет из себя покупку процесса 
нормотворчества (осуществляемого как законодательной, так и исполнительной властью) заинтересованными лицами. Административные органы «захвачены» в том случае, если они регулируют общественные отношения в узкогрупповых интересах. Концепт «присвоения государства» интересует нас постольку, поскольку закон предусматривает возможность (подчас оформляя ее многочисленными отсылочными нормами) «покупки» процесса ведомственного нормотворчества.

Ниже каждая группа будет рассмотрена более подробно.

\section{Завышенные требования нормы как коррупциогенный фактор}

При анализе завышенных требований закона мы будем отталкиваться от следующего набора предположений:

\section{Предположение 1.}

Любая норма права накладывает на индивида некие потери (издержки, обременения, ограничения), связанные с подчинением норме права.

\section{Предположение 2.}

Чем выше потери, которые связаны с подчинением норме права, тем больше вероятность того, что индивид заплатит за возможность не соблюдать норму права или уменьшение потерь.

\section{Вывод из предположений 1 и 2:}

Любой закон коррупциогенен, так как он накладывает на индивидуума либо сообщество индивидуумов некие потери, связанные с подчинением норме права [10, c.53].

Из вышеперечисленных предположений очевидно, что для анализа коррупциогенности необходимо разобраться с понятием правового ограничения, которое налагается на индивида. Некоторые исследователи связывают понятие правовых ограничений с несовершенством закона. «Мы должны помнить о том, что сами по себе нормы могут иметь различное содержание. За- щитники правил ради правил подчас предполагают, что все правила - это хорошие правила. И действительно, если правила задуманы с тем, чтобы противодействовать недолжному и произвольному поведению, они, может быть, и правы. Однако правила могут навязывать некие ограничения, например, требуя исключения социально незащищенного индивида (безработной женщины) из списков на получение социальной помощи вследствие того, что она проживает совместно с мужчиной. Следовательно, правила могут предполагать нерациональное легалистичное поведение, при котором точность исполнения нормы никак не связана и целями организации» [11].

Таким образом, возможность наложения неких правовых ограничений связывается только с «плохими» нормами. Нам кажется, что это - несколько упрощенная картина несовершенства нормы. Исходя из предположения автора, можно сделать следующий вывод: любая норма «плоха» в том смысле, что любая норма накладывает на индивидуума некое ограничение, заставляя его тратить свои ресурсы на соблюдение нормы (как вне конкретного правоотношения, так и посредством создания, изменения, прекращения правоотношения). В соответствии указанными выше предположениями, несовершенство нормы будет состоять в том, что она накладывает на индивидуума больше тягот, чем могла бы. Как же определить, какой размер тягот накладывает норма на индивидуума?

В связи с этим, необходимо подробнее остановиться на двух возможных заблуждениях. Первое заключается в предположении, что отсутствие регулирования, не накладывая на индивида тягот, было бы идеально некоррупциогенным. Вопрос отсутствия регулирования - по преимуществу идеологический. Может быть, он и был бы актуален во времена доминирова- 
ния доктрины государства - «ночного сторожа» и в идеологическом дискурсе либералы того времени могли бы упирать еще и на то преимущество своей идеологии, что она антикоррупционна по сути своей. Но вследствие стирания идеологических отличий и сторонники государственного регулирования, и сторонники laissez-faire допускают регулирование как таковое, но в разных масштабах.

В то же время отрицать зависимость коррупциогенности от идеологической ориентации того или иного закона во всех случаях нельзя. Так, например, либералы «выступают за декриминализацию нарушений нравственных норм, в особенности нарушений, связанных с наркотиками и сексом, при условии, что они совершаются с обоюдного согласия и касаются только взрослых» ${ }^{4}$. Таким образом, вероятнее всего, они будут голосовать за то, чтобы в уголовном кодексе не было предусмотрено наказания за «нарушение нравственных норм». В то же время последняя оговорка дает еще одну возможность убедиться в том, что и либералы, сторонники laissez faire полностью от регулирования общественных отношений не отказываются.

Второе заблуждение касается возможности некоего идеального, экономически эффективного и математически подсчитанного уровня правовых ограничений. Однако, вопрос государственного регулирования или его отсутствия - это вопрос, который разрешается в стенах представительного органа власти, а не в кабинетах экономистов за калькулятором и компьютерными математическими программами, т.е. вопрос ценностный, а не технократический.

Вывод. Введением институтов саморегулирования и со-регулирования и закрепление их в Конституции РМ, позволит значительно ослабить коррупцию.

\section{Политические детерминанты коррупциогенности}

\section{1. Идеологическая позиция законодателя и коррупциогенность}

Более или менее коррупциогенное регулирование определенных общественных отношений зависит от идеологических (ценностных) ориентаций депутатов. В зависимости от своих намерений (которые, так или иначе располагаются на континууме «сильный государственный контроль и регулирование - слабый госконтроль, преимущественное использование экономических мер давления для принуждения к реализации нормы права»), они выбирают более или менее коррупциогенные пути регулирования. Сравнивая последние, объективированные в конкретных законах или законопроектах, можно определить, какой способ регуляции порождает наименьшую (или наибольшую) вероятность заключения коррупционной сделки. Следует заметить, однако, что для применения данного способа необходимо, чтобы конкретный закон или законопроект было бы с чем сравнивать. Иными словами, по меньшей мере, два нормативных документа (независимо от того, вступили они в силу или нет) должны регулировать сходные общественные отношения.

Вывод. Необходимо развивать идеологию саморегулирования и распространять ее в среде предпринимателей, а чиновника приучать к восприятию этого нового института как равного с государственным регулированием. Это ослабит коррупцию.

\section{2. Политическая борьба и коррупциогенность}

Однако, подчас принятие законопроекта определяется не балансом идеологических позиций депутатов, а балансом расстановки политических сил. В этом случае законопроект представляет собой средство борьбы против конкурента на политиче- 
ском поле. Орудием политической борьбы становится закон, заставляющий политических противников затрачивать завышенные ресурсы, связанные с подчинением норме права. Ликвидация партии как мера ответственности за неучастие в выборах в течение пяти лет накладывает на партию больше потерь по сравнению с лишением ее государственной поддержки, но сохранением ее существования. Наиболее коррупциогенной следует признать нормы законопроектов, которые не только предусматривает ликвидацию партии как меру ответственности, но и наделяет административные органы правом подавать заявление в суд о ликвидации.

\section{3. Эндогенная коррупция}

Часть исследователей считает, что факторы, которые определяют коррупцию, носят внешний по отношению к бюрократии характер. Следовательно, они отрицают влияние бюрократов на уровень зарегулированности (regulatory burden; социологический аналог завышенных требований нормы права) и отстаивают, тем самым, идею функциональности коррупции. Их оппоненты полагают, что бюрократы способны намеренно увеличивать уровень зарегулированности с тем, чтобы извлекать большую ренту. Эндогенной коррупции способствует современное конституционное законодательство большинства стран, которое наделяет исполнительную власть широкими полномочиями в процессе законотворчества. Так, во Франции парламент может законодательствовать лишь по ограниченному кругу вопросов, очерченных в ст. 34 Конституции Французской Республики. Все иные вопросы относятся к сфере регламентарной власти, принадлежащей Правительству. Ст. 44 той же Конституции предусматривает процедуру «блокированного голосования», в соответствии с которой по требованию
Правительства палата, рассматривающая законопроект, должна провести единое голосование по всему тексту законопроекта в целом. При этом, она имеет право сохранить лишь те поправки, которые были внесены Правительством. Широкие полномочия в сфере законотворчества исполнительная власть обретает также вместе с преимущественным правом формировать повестку дня - как Сената, так и Национального Собрания.

В некоторых переходных странах конституционный законодатель предоставляет исполнительной власти еще больше законодательных полномочий. Так, согласно Конституции Республики Казахстан, существуют три государственных органа, Парламент, Президент и Правительство, которые полномочны издавать законы (Президент Республики издает указы с силой закона и указы с силой конституционного закона).

\section{4. Особенности бюрократического правоприменения}

Бюрократическая организация далеко не так идеальна для управления современным обществом, как это казалось М. Веберу. Ей свойствен целый ряд недостатков, выявленных социологами и экономистами. Один из недостатков состоит в чрезмерной приверженности бюрократов правилам, которые становятся самоцелью. За конкретными нормами закона бюрократы не видят духа закона. Объяснение этому феномену мы находим у Мертона. «Эффективная бюрократия, - пишет он, - требует надежности реакции и строгой приверженности правилам. Подобная приверженность правилам ведет к их трансформации в абсолют, они не рассматриваются более как средства к достижению некоей цели» [12]. В. Томпсон, называя подобные явления «бюропатологией», связывает их возникновение с организационной специализацией, в рам- 
ках которой руководителю необходимо контролировать своих подчиненных. Акцент на формальных требованиях нормы, а не на ее содержательных аспектах делает бюрократическое правоприменение формалистичным и жестким. Те обязанности, накладываемые на индивидуума, которые были заложены законодателем, в лучшем случае не выпускаются из виду, а в худшем - увеличиваются в процессе правоприменения.

\section{5. Дополнительные потери в процессе применения нормы права}

Требования норм права могут завышаться в процессе правоприменения: либо из-за несовершенства процессуальных норм, в соответствии с которыми должна осуществляться деятельность правоприменителя, либо вследствие несовершенств тех материальных норм, которые устанавливают правовой статус правоприменительных инстанций, допуская «пересечение» контрольных полномочий различных органов.

В первом случае процессуальная норма права допускает наложение дополнительных тягот на индивида, который уже обязан, по закону, понести определенные обременения.

Необходимо, однако, отметить, что весьма часто ведомство самостоятельно присваивает себе контрольные полномочия. Обилие контролирующих инстанций в достаточно узкой сфере надзора делает совершенно невозможной разграничение контрольных полномочий между ними и, тем самым, создает дублирование полномочий.

\section{6. Коррупциогенность отрасли законодательства}

Завышенные требования нормы права могут проистекать из самой организации правового поля. Иными словами, подчас коррупциогенна не норма права, а отрасль законодательства как совокупность нормативных актов различной юридической силы, регулирующих относительно самостоятельную область, сферу общественных отношений. Наиболее характерным примером в данном случае является отрасль законодательства об административной ответственности. Нормы административного права могут содержаться в любом законе и даже в подзаконном акте. В результате действия этого положения в настоящее время административная ответственность устанавливается огромным количеством законов и подзаконных актов. Это заставило некоторых авторов говорить о «размывании единого правового поля административных правонарушений» [13, с.44].

\section{Заключение}

Таким образом, на основе проведенного нами исследования можно сформулировать следующие выводы и предложения:

1. Необходимо изменить избирательное право и избирательный процесс поскольку посредством электоральной коррупции, коррупция проникает в государственную систему всех ветвей власти, поражая государственный механизм целиком. В новой Конституции необходима норма, запрещающая избранникам отдельных партий уже после их избрания в Парламент РМ или местные органы власти переход из одной партии в другую, вплоть до уголовной ответственности.

2. Следует развивать организации саморегулирования предпринимателей и ослаблять коррупцию или даже ее искоренять, за счет делегирования им некоторых функций государства. В новой Конституции РМ предусмотреть ст.33* «Свобода предпринимательской деятельности и саморегулирования» (примерные формулировки этой статьи см. выше). Принять закон РМ «О саморегулируемых организациях». 
3. Помимо введения институтов саморегулирования, появится возможность развивать и совместное регулирование у государства и саморегулируемых организаций, то есть со-регулирование, что, также позволит значительно ослабить коррупцию.

\section{Библиография}

1. БОНДАРЕНКО, С.В. Коррумпированные общества. Ростов-на-Дону. 2006.

2. POSNER, R.A. Economic analysis of law. N.Y. 1977 , p. 465.

3. Подробно об этом см.: Игнатьев В. О новых инструментах в системе правового регулирования малого предпринимательства/Закон и жизнь, 2005, с.13-17.

4. История борьбы с коррупцией в Китае излагается на основе: F. T. Lui. Corruption deterrence // Journal of public economics, 1986, Vol. 34.

5. MURDAL, G. Asian drama. 1968, p. 938. Цит. по: F. Т. Lui. Op. cit. p. 232.

6. Подробно об этом см.: Игнатьев Василий. К вопросу о возникновении понятия «посредничество» и его роли в современном развитии форм малого предпринимательства/ Закон и жизнь, 2007, № 5, с. 10.

7. Конституции зарубежных государств. М.: Волтерс Клувер, 2003.

8. Конституция Украины. Киев: Высшая школа, 1996. В тексте Конституции Республики
Молдова подобной статьи нет. Подобная статья должна быть сформулирована в ее разделе II «Основные права, свободы и обязанности».

9. Подробно об этом см.: Игнатьев, В.П. Саморегулирование в малом предпринимательстве. - «Дні науки 2005»: Матер. Международнойї науково-практичноі конференциї. Том 28. Юридичнї науки. Юридичні науки - Дніпропетровськ: Наука і освіта,2005, с.71-73.

10. Ниже вместо понятия «несовершенство норм права, повышающих вероятность коррупции» будет использован термин «коррупциогенный фактор», предложенный С. В. Максимовым. Автор определяет его как «явление или группа явлений (факторный комплекс), порождающих или способствующих порождению или росту коррупции». См. Максимов С.В.. Коррупция. Закон. Ответственность. М., 2000. C. 53.

11. К этому же выводу пришел и Макмиллан, отмечавший, что, «раз все законы ставят некоторую группу людей в невыгодное положение (put some group at a disadvantage), эта группа становится потенциальным источником коррупции». (См.: McMullan A theory of corruption // The sociological review, Vol. 9 1961, p. 196)

12. MERTON, Robert. Bureaucratic structure and personality // Social forces, Vol. 18 (1940). В кн.: Classics in public administration, p. 111.

13. ДВОРКИН, Р. Либерализм. - В кн. Современный либерализм. М., 1998. С. 44. 